\title{
AN -ALTERNATIVE INTERPRETATION OF INDUSTRIAL PROMOTION POLICY: THE MONGOLIAN EXPERIENCE
}

\author{
Summit Kuribayashi
}

\section{Introduction}

Since the partial collapse of the Cold War structure in Northeast Asia (NEA), there has been a profound transformation of economic landscape in the former centrally-planned economies-Mongolia, Russia and China. Despite a broad spectrum of market-oriented economic policies being instituted and promoted over the past few years, the results are mixed. Specifically, the economic performance of Russia and Mongolia is far from satisfactory. Moreover, the extensive change in economic system has not yet been completed. Although such outcome is inevitable, a close examination of this transition effort may be useful to reconsider the desirable policy objectives, outcomes and processes of systemic transformation in these countries.

Against this background the objective of this paper is two fold. First, with particular reference to the transition process in Mongolia, the paper intends to review the industrial promotion policies that have been instituted since 1990 . Second, the paper aims to derive several relevant lessons from the Mongolian experience in rethinking the industrial promotion policies for re-industrialization in the transitional economies.

\section{Changes of market conditions in external sector}

By and large, the transformation to market-oriented economic system in the NEA was started as the consequence of the collapse of the former Soviet Union and CMEA regime. Mongolia was a typical example. Before 1990, Mongolia had an extremely high dependent economic structure on the CMEA regime. For instance, 95 percent of its international trade was carried out through the transaction with CMEA countries. However, the trade structure has changed rapidly since 1990. Consequently, trade volume with former CMEA countries contracted, while economic and military assistance from Russia were stopped.

Russian Far East (RFE) also encountered similar experience. After the collapse of the division of labor structure between RFE and other regions in Russia-which arc mainly located at the western side of Ural Mountain, RFE's economy was isolated. Furthermore, North Korea also received tremendous impact from the collapse of the former Soviet Union. 
Under such circumstances, what are the desirable economic policies to promote the development of market-oriented? Systems in these countries? China provides plausible alternative direction. China started to transform its centrallyplanned economy to the market-based one in the late 1970's. The economic transformation process is mainly driven by domestic market liberalization and outward looking policies. Indeed, these policies provided a basis to rapid expansion of export and attraction of enormous amount of foreign direct investment. Consequently, China was able to achieve remarkably high growth-real GDP growth a year was 10.2 percent between 1980 and 1995 .

The population of Mongolia, RFR and North Korea is 2.3 millions, 8 millions and 20 millions, respectively. Thus, the size of the domestic market is too small in comparison to China. Small domestic market inhibits economy of scale. For this reason, setting up full set industrial structure is not feasible in those economies. Rather, what is needed is the "Structural Specialization Policy". Under such framework, the industrial structure specialized on products which have international comparative advantages in exports. Other necessary products are complemented by imports.

Hi other words, Mongolia first needs to re-orientate its industrial structure and economic relations to the former Soviet regime. Secondly, in medium and long-term perspective, Mongolia should undertake structural transformation for trade expansion to the market-oriented industrialized countries. For this purpose, appropriate industrial policies, which includes export promotion policy package, become extremely important.

\section{Changes of the economic conditions; inflation control and macro economic stabilization.}

Hi Mongolia, import goods such as machinery components and oil from Russia decreased rapidly after the collapse of the former USSR. This supply shortage compounded with price liberalization induced high inflation in Mongolia. Consequently, Mongolian national currency-tugrik, which was linked to transferable Russian ruble, had to be put into a new adjustment process. During this transformation process, instead of the aid from former USSR, substantial amount of economic -assistance from international organizations such as IMF, ADB and developed countries like Japan and United States have been injected into the Mongolian economy.

At the same time, however, the conditionality attached with- the assistance from international organizations exert tremendous pressure on Mongolia. The purpose of the conditionality is to establish macro economic stabilization. 
As a result, strict control on money emission by hard budget constraint was introduced. Evidently, this reform package was the most crucial point in the Mongolian economic history.

\section{Grope for new market system and the realities in Mongolian economy}

At this stage, Mongolia has demonstrated strong efforts to transform its economic system to a market-oriented one. Various regulations were liberalized, international trade permission system was abolished, and fixed foreign exchange system was replaced with floating exchange rate regime. In addition, regulations on the prices were gradually modified, state owned enterprises were privatized and stock exchange market was established in order to promote the development of a market economy. Financial subsidies were heavily cut, the numbers of administrative officers were reduced in order to improve budget deficit. In order words, the effort to set up a small government was promoted.

The transition mentioned above seems to be very rational; however, when this process is evaluated carefully, one can find many contradictions exist between the IMF-IBRD type of economic policies and the reality. IMF has a tendency to recommend policies based on their tradition- neo-classical economic theory, which they have fostered. That is, the priority of the IMF's reform strategy is to ensure macro stabilization through balanced budget, trade balance and low inflation. One of the most important policy instruments in this reform program is the monetary policy.

On the other hand, IBRD and ADB incline to recommend policies that are to promote project based finance smoothly and successfully because they are "the bank". The key issue whether the projects are successful or not depends on the internal rate of return (IRR). In other words, rational calculation of IRR is required for each project. The condition to undertake rational calculation of IRR depends on the market mechanism which operates under the premise of perfect competition. For this reason, international multilateral financial institutions assert strongly to the abolishment of regulations, minimum administrative organizations, institution and state-owned enterprises because these elements strongly distort market or price mechanism. In other word, this is a "free market, minimalist state" of neo-classical paradigm.

\section{Scrap without built}

One of the fundamental problems on the recommendations mentioned above is the following. The policies for macro economic stabilization and small 
government give raise to the contraction of production, which as a result, creates a situation where the economy is scraped without built.

\section{4-1. Privatization: an assessment}

The mass privatization of the state-owned enterprises was carried out by the instantaneous approach which had been used in Russia and East European countries. This privatization strategy encompasses four stages. First, a crude assessment of the total asset of the targeted state-owned enterprises is carried out. Second, privatization vouchers (voucher value is derived from dividing total assets by the total number of the population) are distributed to each citizen. Third, the citizens select one or two enterprises in exchange of the vouchers, whereby a citizen group which bided the highest price acquired the ownership of those enterprises. In the last stage, stock exchange is created to facilitate the exchange /flow of vouchers, which in turn is expected to bring about the concentration of ownerships. However, the real situation differs significantly from the intended objective of such mass privatization program. For instance, ten or twenty thousand share holders exist in each enterprise. The problem of who actually holds the final management responsibilities remains either unresolved or ambiguous. Most importantly, such "giveaways" privatization created many private share holders without the necessary capital to rebuild the privatized enterprises for economy recovery. Rather, many privatized enterprises have had to take over a large amount of debt to the banking sector as a result of the loans accumulated before privatization process. Consequently, many enterprises are confronting with a severe situation where they are even unable to service the interest of the loan. Money supply control policy that has been instituted in order to attain macro stability and low inflation rule out any opportunities in which enterprises can borrow working capital for the continuous production activities. As a consequence, most enterprises have to sell out products which are stockpiled. After they received some money from the sale, then they procure the raw materials, and then re-start the production line. When some volume of goods has been produced, the production line is halted in order to sell the goods for input procurement. Furthermore, this typical vicious cycle in the real sector is compounded with many other impediment factors such as electric power shortage, machinery parts shortage and so on that inhibit the production activities.

\section{4-2. Agricultural sector}

The collapse of the former state-owned big scale agricultural farms gives 
rise to inefficient use of capital inputs such as tractors, trucks, chemical fertilizer, and agricultural chemical. As a result, for example, in 1995 the production level of wheat declined to 40 percent of 1990's level. In the nomadic sector, .privatization of the ownership of the livestock gave nomadic people strong incentives to increase number of livestock's. However, because the collapse of the former state-owned distribution, system, nomadic people can not find the appropriate channel to bring livestock related materials (such as meat, milk, , leather, wool) to the processing factories which are located in the urban area. Consequently, the stock of the raw materials inevitably increases and cash revenue decreases in rural area.

\section{4-3. Government sector}

Cutting financial expenditure reduced labor incentives of the administrative officials. Their living standard has deteriorated, whereas the corruption is becoming increase severe. Furthermore, salaries to the teachers are delayed, there by brought about regular strike movements in the local area, which in. turn forced many schools to close for long duration. The targeted area for the reduction of financial expenditure has been extended to»the staffs of the ODA related sectors. For this reason, ODA approval procedure is often delayed. The numbers of ODA projects that are forced to be terminated by such financial constraint have increased. In addition, research institutions whose aim is to inquire economic and social policies are confronted with the acute shortage of research funds. Thus, personnel are leaving research institutions have accelerated. The ability of the statistical sector in the government has also declined because of the decreasing staffs. Therefore, the reliability of the statistical data and the capacities of the economic research which are of utmost important to the policy making process have also deteriorated. Furthermore, the downsizing of the social security and welfare systems has also resulted to the decline in living standard of the most poverty group day by day.

\section{What are the bottlenecks?}

What are the causes which produce difference between the market-oriented policies and the realities? It seems to me that the thinking of the international financial organizations is not totally incorrect. It is very clear that any reform policies can not achieve their policy objectives in the state of distorted macro economic conditions. The concept of a small government is also correct under the hard budget constrains. However, the problem is that there are no 
policies other than the two policies-the macro stabilization policy and small government oriented policy. IMF is confident that market mechanism can be created in a short time by the shock therapy. This fundamental belief lies on the assumption that once market mechanism is set up, the economy automatically induces development. This is a too simple economic thought!

Many other appropriate policy measures are required to coexist with the macro stabilization policies in order to produce real economic development. For example, institution building (such as creation of private and public organizations that are capable of carrying out investment, trade, competition and technology policies) and capacity building on human resource development. In addition, it needs a long time to develop and nurture the market mechanism.

\section{5-1. Priority production strategy}

Priority production strategy encourages the government to allocate the scarce financial resources to those important industrial sectors and yet be able to maintain a money supply level that keeps macro economic stable as well. The twin objectives of allocation of financial resources for priority production and macro economic stabilization can be achieved by the following approach. The central bank is required to check the financial structure of each commercial bank in order to identify unnecessary financial allocation to the sectors which are not so important for the economy and have no urgent financial needs. Instead, the central bank orders to strengthen the financial allocation to the sectors which are very important and have urgent financial needs for the country concerned. This is one of the policies which are urgently needed in Mongolia.

\section{5-2. Real interest rate policy}

Another useful policy instrument to consolidate the working capital for enterprises is the real interest rate policy. It is true that the real interest rate must be positive in order to achieve profitability in the banking activities. Too high that the real interest rate such as 30 percent a year in Mongolia in 1995 was a clear reflection of economic rationale-profit maximization of banking activity, but it has no practical implication. Thus, what is essential is to decrease the rate as low as possible for the selected important industry or enterprise. In fact, high interest rate policy represses the demand for finance and it deteriorates profit structure in the banking sector. As a result, this leads to a discreet attitude in the banking sector, and inevitably, it prompted the financial institutions to seek higher interest rate. This is clearly a vicious cycle. 
Moreover, there is further ground to reconsider the assertion of positive real interest rate (nominal interest rate minus inflation rate). In general, inflation rate itself is produced in an average rate basis. Inflation rates in different sectors are different from each other. Thus, comprehensive financial policies to encompass the inflation rate in each individual sector must be promoted.

\section{5-3. Investment policy for improved efficiency}

Market mechanism is a basis for optimum resource allocation. This statement is true if and only if the other things being equal. In other words, if the other things change, there is a high possibility that this statement is not valid. Suppose there is one industrial sector or enterprise. If the government promotes a policy which supply good infrastructure or new technology to this selected sector / enterprise, then it will help to strengthen the competitiveness? It should be noted here that the efficiency is different before and after the selective intervention. Thus, before or after the policy, the government makes them throne to the market mechanism, there are other instruments, such as appropriate investment policies, to improve efficiency. Timely government support through investment policy is important to ensure effective operation of reforming enterprises in market-oriented environment.

\section{5-4. Small but effective government}

We have to reconsider the small government oriented policy too. If small government plays a small role, then it only means weak government. Given such situation, the economic development will be doubtful. Thus, a small government must be sufficiently effective on nurturing market mechanism on one hand, while promoting long-term appropriate resource allocation policy which is different from the short-term resource allocation mechanism in the market.

\section{5-5. Human resource development}

To ensure effective government and enhanced capacity to carry out comprehensive industrial promotion policies, human resource development of the administrative personnel is of utmost importance. Short-term training in abroad is one of the most effective approach to improve the administrative and development management capacity of bureaucrats. But, it should be noted that, from the Mongolian experience, two or three weeks training in abroad is insufficient to fully understand the function of market economy. Contrary, there is a possibility that the governmental officials may accept market economy superficially, 
while do not approve of it in their true mind and protest negatively in strengthening the market mechanism. More importantly, if we lack of the human resource development policies, there is a high possibility in which small government is transformed into an inefficient and bureaucratic one immediately, which in turn impedes development process. The area of the human resource development program does not solely confine to the administrative level. It has to encompass other fields such as human resource development in the enterprise level. Particularly, government should provide human resource development support to those promising enterprises which are facing transformation obstacles under difficult economic conditions. For example, the government should facilitate the enterprises to carry out the study of the experience in the much modernized enterprises.

\section{The lessons from other NEA countries}

The experiences of economic development in Japan, South Korea and China show the following lessons. That is, a growth sector has to be fostered in the economy by the appropriate industrial policies at the very initial stage of development. Japanese and South Korean experiences also clearly demonstrate that as the economy continues its expansion, various problem or weak points in the economy will be overcame and which in turn help to foster the market.

China also demonstrates some useful lessons. For example, the core of the growth sector was formed by the private enterprises which were founded by the new entrepreneurs in China. Since the introduction of economic reform and open door policies, small size enterprises in rural area, that is, township and village enterprises have been expanding rapidly. On the other hand, the share of the state owned-enterprise output in GDP has been decreasing. Although the inefficient management of the state-owned enterprises still remains a big challenge in the on-going reform process, China has sufficient time and strength to cope with this problem at present. The way which the problems are postponed is useful under the specific condition. Chinese experience in economic reform provides many useful suggestions to the transitional economies in NEA, especially North Korea in the near future.

\section{What have to be done?}

\section{7-1. Multilateral international financial institutions}

International financial organizations have to re-examine their decision making process. The experts in IMF, IBRD and ADB know that there is no similar 
economic structure and same economic mechanism through developing economies in the world. But, these experts can not present individual case according to the unique situation in each individual country to the board of directors which is represented by many countries. If the experts bring up individual case, the board will turn into chaos and no consensus in policies making will be able to constitute. For this reason, the staffs of international financial institutions have to bring up minimum sized and easy consensus oriented proposal to the board. As a result, when experts visit the developing country concerned, they often bring tremendous volume but simplified manual. Most of the time, they promote customized procedure to study based on the same manual in another developing countries. Even the country economists, they only visit the country concerned for a short time and in a good weather seasons. Also, the study results often neglect factors which are beyond the coverage of such manual? Thus, international financial organizations have to make more efforts to reach correct understanding of the total economic situation in the country concerned.

\section{7-2. Bilateral assistance}

ODA donor countries sometimes have a different philosophy about economic policies with that of the international organizations. For example, Japan and South Korea understand that nurturing market mechanism takes long time. These countries understand that macro economic policies are necessary but not sufficient enough to control the turbulence in the market. Therefore, direct administrative guidance is necessary in the transition period. However, their philosophy does not reflect in the real world. The reasons are as follows.

First, these donor countries are also important members of the board in the international organizations. For this reason, they are not able to deny easily the proposals which have approved in the board meetings. Second, ODA promotion procedures are usually preceded by the cooperation among different ministries, particularly in Japan. It is not easy to reach national consensus between implementing ministries on specific ODA related policies in a short period.

In general, political leaders in transitional economies are confronted with difficult problems day by day. When they feel a difficulty in a policy making process, they want to seek the opinions from the international organizations and donor countries. Because IMF, IBRD and ADB are organizations which have a clear hierarchy, they can correspond $X o$ the questions quickly. On the other hand, donor countries can not cope with those questions in a short time. 
As political leaders in developing countries are being irritated by waiting the answer, it is quite natural that they inevitable have to rely on the opinions coming from international organization as an important advisory input without carefully consultations.

So, for donor countries, improving efficiency on the decision making process for economic assistance, in particular, the policy level cooperation is needed. Also for the government of the developing countries, it is needed that an attitude which consider or discuss the proposals from outside of the countries in a calm frame of mind.

\section{The necessity for correct understanding of the industrial}

Industrial policy is one of the most effective measures to enhance the strength of the strategic industrial sector for economic development under the conditions which market mechanism can not function smoothly. Here, it is to be emphasized that industrial policy is not a policy which denies market system.

Japanese experience suggests that the industrial policy which has emphasized on market information is a successful one. For example protection- policies through import quota and high tariff barrier for infant automobile industry contributed to the prosperity of the industry in nowadays. This policy predicted future demand expansion of automobile despite small demand that had existed in those days. On the other hand, protection policies for aluminum refinery industry after the first oil shock resulted to a complete failure. This was because the policy did not anticipated the rapidly increase in oil price would affect energy prices which directly constituted about 80 percent share of the total refinery cost.

Japanese experience mentioned above seems to give valuable lessons to the present NEA countries. The essential point is the ability to predict the dynamic change of industrial policies is being interpreted one snidely -state intervention to the market mechanism. The term of intervention involves bad or malicious meaning. It should be emphasized that industrial policy is not an intervention. Thus, we have to keep the distinction between industrial policy and state intervention.

Further, one dangerous trend should be carefully considered here. That is, when one policy produced a wrong result, people like to interpret them as a mistake of the way of thinking of the whole industrial policy itself. Following example suggests some lessons. 
Former Mongolian government prohibited the export of cashmere raw materials. This is because export prohibition was thought to be useful for the domestic cashmere processing industry in terms of value added processed products for exports are profitable to the macro economy. On the contrary, ADBJMF and IBRD all opposed severely to such export restriction.

The result was as follows. Under the export restriction policy, cashmere industry did not develop as expected. Consequently the nomadic people who are living remotely from big city or center of the each state (amok) was not able to sale their cashmere related raw materials because of export restriction policy. As a result, poverty in the rural area was aggravated.

Newly established government liberalized cashmere related raw material export because they could not stand up to the pressure from international organization. ADB, IMF and IBRD asserted as follows. After all, cashmere industry did not developed under the export prohibition policies. This means that the free trade policy is better than the export ban. On the other hand, there are two kind of different opinions in the Mongolian government. First, this policy change is dangerous because the possibility of the collapse of the cashmere industry has increased. Second, the cashmere industry did not develop as execrated is a fact. Does this imply that the industrial policies whose concept brought from Japan, South Korea and China is not so conform to Mongolia?

What was wrong? The problem is that Mongolian cashmere industrial policy was constituted only by the export ban. Other necessary policies such as low interest financial policy, new machinery with high technology, import or lease policies, improvement of procurement system policy, were not introduced to the industry.

Under the present situation, export liberalization on the cashmere materials is justified because the policy can contribute to assist poverty of nomadic people in the rural area out of difficulty. However, when promotion policies for nurturing the cashmere industry have been put in place, then it is rational for the government to restart the export ban policy.

\section{Conclusion}

The economies in NEA are undergoing a dynamic change everyday. In this situation, to make decision on the appropriate policies and put them into practice are highly difficult task. The important point of view is that policy makers have to keep their mind cool and must not regard the industrial policy as one which is opposed to market mechanism. Furthermore, the policy makers 
must not promote policies hastily. Each policy measures must be carefully scrutinized and be organized into appropriates a policy package. In addition, they have to keep an important point that any appropriate policy needs appropriate timing. On the decision making process, it is a normal way that the government, international organization and donor countries pose each opinions, but the government has to make a final decision. For this purpose, even though a small government under the hard budget constraint, the sector in which policy making, decision making and its proceeding, have to be strengthened. Therefore,

International. Financial organizations and donor countries need new assistance scheme which could contribute to the improvement of the policy making capacity in the developing countries in NEA. 